\title{
Spatial distributive justice and crime in the covid-19 pandemic
}

Anthon Dixon ${ }^{1}$, Eric Halford ${ }^{2}$, Graham Farrell ${ }^{1}$

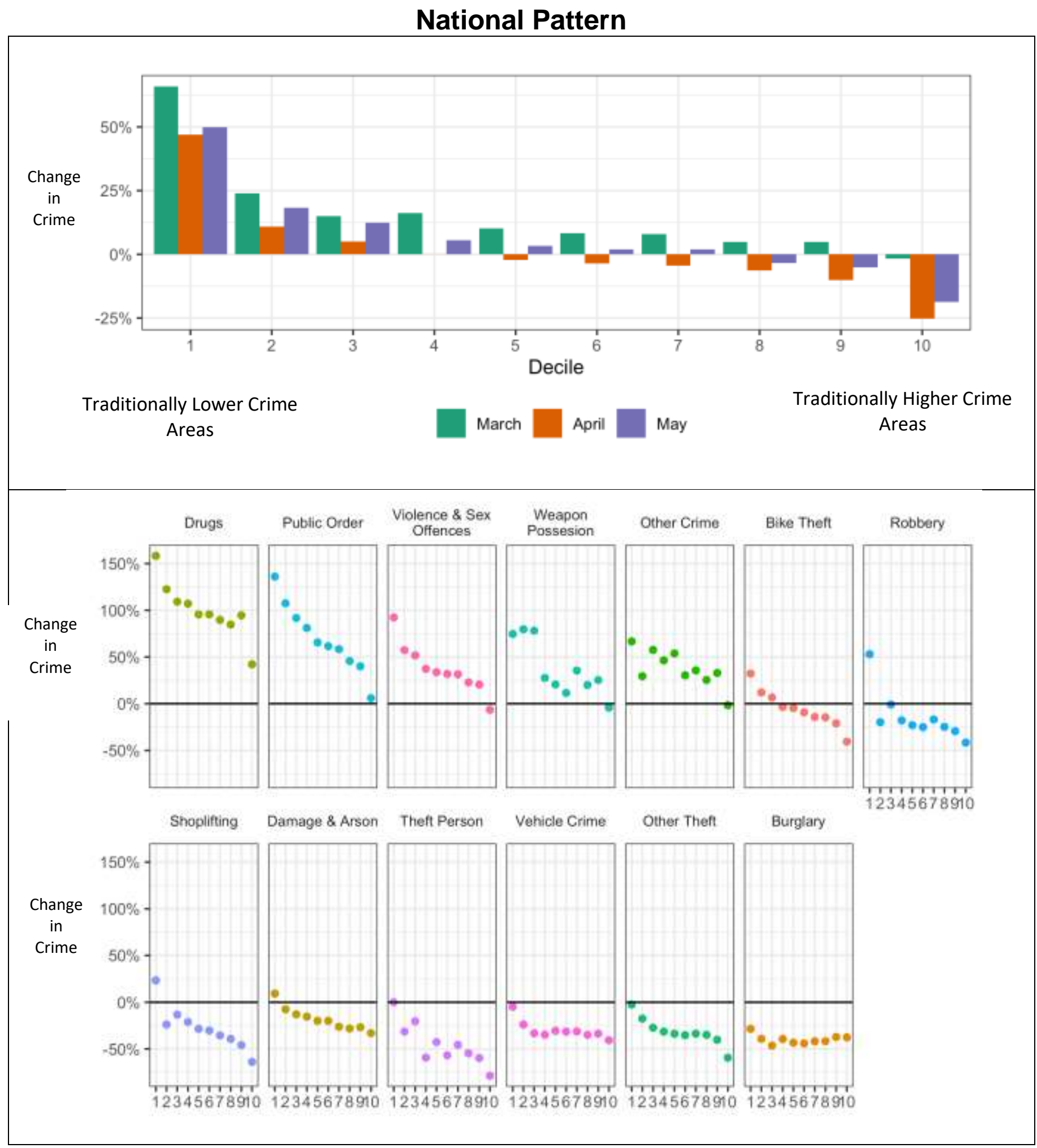




\section{Lancashire Case Study}

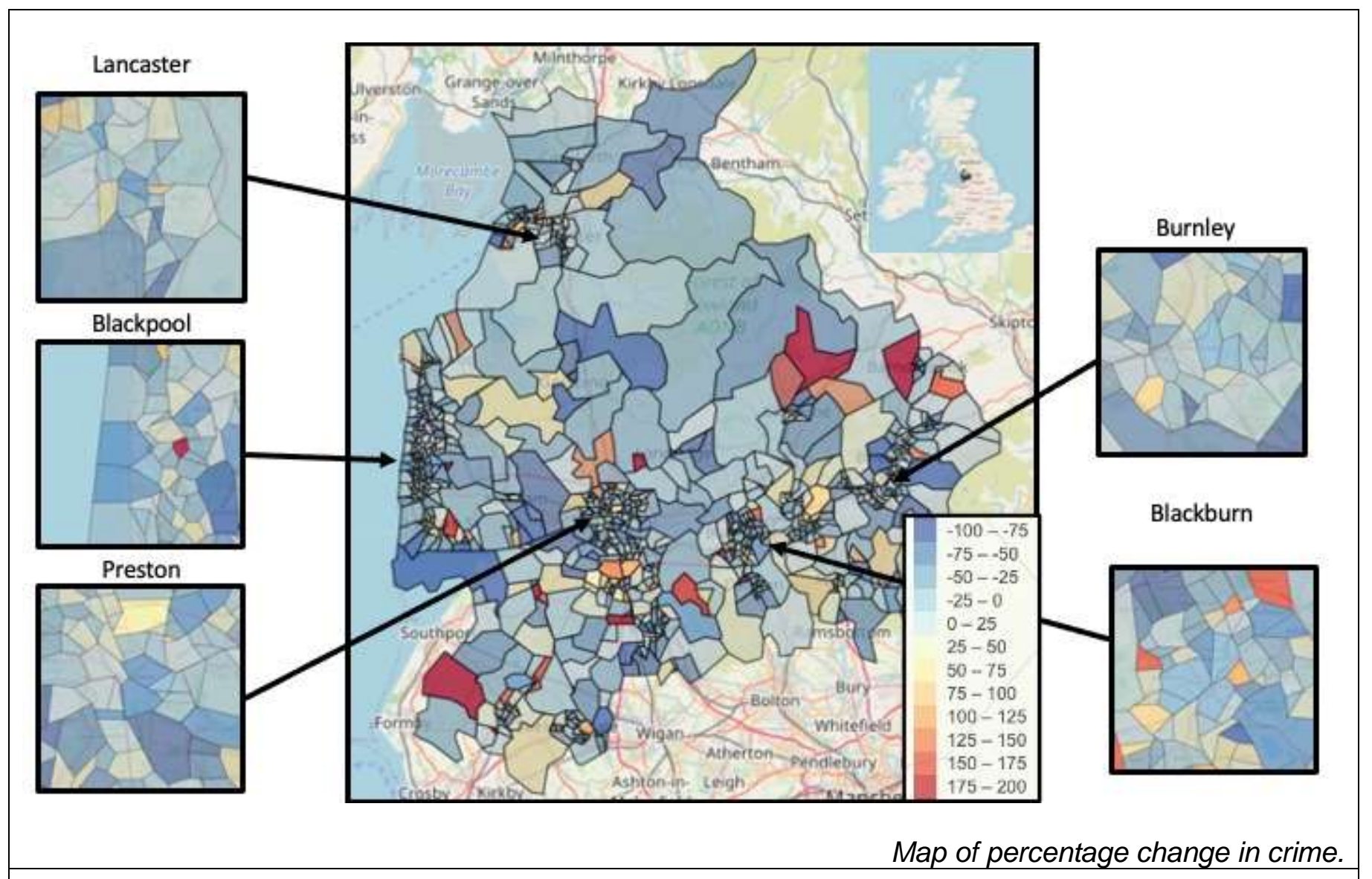

\section{Bizarro World?}

Nationally, small area (LSOAs) were ranked by recorded crime rate and grouped into deciles. Decile rates are changes relative to the rate expected based on the previous five years.

Key findings:

- Previously high-crime areas saw the largest crime declines.

- Previously-low-crime rate areas experienced crime increases.

- Urban centres saw the greatest crime drops in absolute (but not necessarily relative) terms.

- Public order crime increases likely reflect breaches - or perceived breaches - of lockdown rules.

Some crime increases, including drugs and weapon offences, may reflect changes in police activity.

Source: data.police.uk for England, Wales and Northern Ireland; Lancashire Constabulary. Full maps at: https://goofy-fermat-152b72.netlify.app/

\footnotetext{
Reference as: Dixon, A, Halford,E., and G. Farrell (2020). Spatial distributive justice of crime in the covid-19 pandemic, Statistical Bulletin on Crime and COVID-19 Issue 2. Leeds: University of Leeds.

(C) The Authors (2020). DOI: http://doi.org/10.5518/100/26 . ISSN: 2634-4424. This work is licensed under a Creative Commons (CC-BY 4.0).

This research was funded by the Economic and Social Research Council under the UKRI open call on covid-19 under grant ES/V00445X/1.
} 